\title{
Mass transfer analysis considering gas phase diffusion and experimental verification for surface painting a waterborne MCI in concrete
}

\author{
X. Wang, ${ }^{1}$ Z. Liu, ${ }^{1} *$ Z. Wang ${ }^{2,3}$ and N. Song ${ }^{1}$ \\ ${ }^{1}$ School of Civil Engineering, Yantai University, Yantai 264005, China \\ ${ }^{2}$ School of Materials Science and Technology, Southeast University, Nanjing 211189, China \\ ${ }^{3}$ Department of the Built Environment, Eindhoven University of Technology, P.O. Box 513, \\ 5600 MB Eindhoven, The Netherlands \\ *E-mail: $\underline{\text { lzy1698@163.com }}$
}

\begin{abstract}
The mass transfer numerical model including the long-term gas phase diffusion of a waterborne migrating corrosion inhibitor (MCI, named PCI-2016) in concrete was investigated in this study. The PCI-2016 was prepared by using multi-compound and chelate-induced techniques. The concentrations of nitrogen in different thickness of cover concrete after surface-painted different amounts of PCI-2016 were calculated by this mass transfer model. The calculated data were basically consistent with the nitrogen contents tested by Kjeldahl method at interface between steel bar and mortar matrix. To verify the anticorrosion performance of painting PCI-2016 steel bars bedded in mortar specimens containing different content of $\mathrm{NaCl}$ painted with relevant amounts of PCI-2016 were also investigated by the linear polarization resistance (LPR) and electrochemical impedance spectroscopy (EIS). The results revealed that the $I_{\text {corr }}$ of steel bar in the specimen containing $1.25 \% \mathrm{NaCl}$ (wt. to cement) after painting with $5 \mathrm{~g}$ PCI-2016 for 3 days and 28 days decreased from $0.67 \mu \mathrm{A} \cdot \mathrm{cm}^{-2}$ (before painting) to $0.25 \mu \mathrm{A} \cdot \mathrm{cm}^{-2}$ and $0.06 \mu \mathrm{A} \cdot \mathrm{cm}^{-2}$, respectively. The numerical analysis and test results supported that the gas phase transfer model is suitable to calculate the weight of PCI-2016 at the interface zone between steel bar and concrete, and the painted the certain amounts of PCI-2016 on the surface of mortar could show an identified repairing effect on the corrosive steel bar.
\end{abstract}

Keywords: mass transfer; gas phase transfer model; migrating corrosion inhibitor; nitrogen content; anticorrosion performance.

Received: September 9, 2018. Published: January 10, 2019

doi: $\underline{10.17675 / 2305-6894-2019-8-1-2}$

\section{Introduction}

Steel corrosion is the main problem of concrete structure damage in chloride environment, which caused enormous economic losses [1]. In recent years, great progress has been made in the research and development of organic corrosion inhibitors [2-5]. Due to the low cost 
and easily application, using corrosion inhibitor has become a promising method to protect and inhibit the corrosion of reinforcements in concrete constructions.

In our previous studies, the transport and anti-corrosion mechanism of MCI with different molecule structures in chloride solution [6] and concrete structures [7] have been studied [8]. The transport and application models of reactive and non-reactive MCI in concrete structure have been established on the basis of the water transport model $[9,10]$ in concrete. A quantitative model for the relationship among $I_{\text {corr }}$ of steel bar, MCI concentration in steel-concrete interface and water-soluble chloride content in concrete was proposed via multivariate nonlinear statistical analysis with software [11]. According to a large number of repetitive electrochemical and microscopic tests results, the tested MCIs show the good transport and anticorrosion performance in concrete specimens, by which MCI molecules can through the cover concrete easier and then absorb on the surface of steel bars stable. After the MCI molecules formed a dense layer on the steel bar surface, the steel bar can be protected from the chloride corrosion and the corrosive steel bar can be rehabilitated [12]. The critical concentration was also studied. The results showed that the critical chloride concentration increases exponentially with raises of MCI concentration in the solution. Within a certain chloride ion concentration range, the critical MCI concentration for repairing the corroded steel is also increases exponentially with enhancement of chloride content in the solution [13]. These tested MCIs in our studies have been applied on several concrete structure projects in marine environment in China [14]. In recent years, the mechanism and effects of migrating corrosion inhibitors have been extensively studied $[15,16]$. However, not so much works focused on the mass transfer process of migrating corrosion inhibitors in concrete. The transport mechanism and transport law of MCI in concrete is of great significance to optimization design of MCI composition and improving the transport rate and inhibiting efficiency of MCI in concrete.

\section{Model introduction}

\section{Short-term transport model}

Based on former study, the transport process of reactive MCI in cement-based materials can be simulated by the modified MCI transport model [7]. $D(S)$ is the equivalent permeability coefficient of MCI in transport model. $D(S)$ of reactive MCI can be calculated by the following equation:

$$
D(S)=\phi(S)^{\alpha}(1-S)^{\beta} \frac{1}{\rho_{l} \phi(s)}\left[\frac{K}{g}+D_{M v} \frac{M \rho_{v}}{\rho_{l} R T}\right] \times \frac{2 B \gamma}{[\ln (1-S)]^{2}(1-S)}
$$

Where $\phi(S)$ is concrete porosity; $D_{M v}$ is the equivalent diffusive coefficient of MCI in gaseous phase in concrete $\left(\mathrm{m}^{2} / \mathrm{s}\right) ; S$ is variable liquid phase saturation of MCI in concrete; $K$ is permeability coefficient of inhibitor in liquid phase in concrete $(\mathrm{m} / \mathrm{s}) ; \gamma$ is the surface tension of inhibitor $(\mathrm{mN} / \mathrm{m})$; $\mathrm{R}$ is the perfect gas constant $(\mathrm{J} / \mathrm{mol}) ; M$ is the molar mass of 
inhibitor $(\mathrm{kg} / \mathrm{mol}) ; T$ is the absolute temperature of environment $(\mathrm{K}) ; g$ is the gravitational acceleration $(\mathrm{N} / \mathrm{kg}) ; \rho_{l}, \rho_{v}$ are the density of inhibitor in liquid and gaseous phase respectively $\left(\mathrm{kg} / \mathrm{m}^{3}\right)$; the constant $B$ is the peak value of pore distribution in concrete, when W/C are 0.55 , the $B$ values are $9.6 \times 10^{6}$, respectively. $\alpha$ and $\beta$ are coefficients fitted by experimental data.

\section{Long-term gas phase transport model}

In order to simplify the problem, the concrete structure is generally regarded as an isotropic and uniformly continuous porous medium. A diffusion equation based on Fick's second law can be used to describe the diffusion process of PCI-2016 gas in concrete structures.

In the derivation of the model, it is assumed that the concentration of gas phase PCI-2016 in the concrete is distributed along a straight line at the gas-liquid interface. Then the gas diffusion plays a leading role, while other effects can be ignored. According to the conservation of mass, the following mass conservation for gas phase can be obtained (Formula (2)). PCI-2016 mass flux at liquid phase plus the evaporation rate of liquid PCI-2016 in a region equals the change rate of gas phase PCI-2016 mass in that region.

The equation can be expressed as:

$$
\frac{\partial m_{v}}{\partial t}=j_{v} A+\theta_{M v}
$$

Where $m_{v}$ is the weight of the gas-phase MCI for this region, $\mathrm{kg} ; j_{v}$ is the mass flux of steam diffusion, $\mathrm{kg} /\left(\mathrm{m}^{2} \cdot \mathrm{s}\right) ; A$ is the sectional area of a region, $\mathrm{m}^{2} ; \theta_{M v}$ is the evaporation rate of liquid PCI-2016, $\mathrm{kg} / \mathrm{s}$.

The initial condition is $t=0, P_{\mathrm{v}}=0\left(P_{\mathrm{v}}\right.$ is the vapor pressure for the area, Pa). The boundary condition is $x=0, P_{\mathrm{v}}=S_{\mathrm{P} 0} ; t \geq 0, x=\infty, P_{\mathrm{v}}=0$ ( $S$ represents the saturation at the gas-liquid interface, $P_{0}$ represents the saturated vapor pressure at the gas-liquid interface).

Formula (2) is the gas phase PCI-2016 diffusion equation based on Fick's second law. The vapor pressure distribution of the gas phase PCI-2016 in the concrete structure at any depth and time can be obtained by solving that equation, and then the concentration distribution of the gas PCI-2016 along the concrete can be obtained.

Generally speaking, each PCI-2016 layer needs 4 hours for drying on the surface of mortar specimens. Approximately, the penetrating process in this period is treated as one-dimensional saturated capillary absorption of MCI. The chemical parameters of PCI-2016 are taken into the short-term liquid transport model. Then the penetration depth and permeation amount of PCI-2016 in concrete block are calculated with different coating applications of PCI-2016. The saturated vapor pressure of PCI-2016 and the initial boundary conditions are taken into the long-term gas diffusion model. Then the distribution of gas PCI-2016 concentration in concrete specimens can be obtained. 


\section{Experimental}

\section{Sample preparation}

Mortar specimens were made of Portland cement (P.I 52.5), Chinese standard sand and potable city water. The chemical composition of cement is listed in Table 1. The mechanical properties and porosity of mortar are listed in Table 2. The water to cement ratios $(\mathrm{W} / \mathrm{C})$ of specimens was 0.55 . The sand to cement ratio was 3.0. The size of specimens was $70.7 \times 70.7 \times 70.7 \mathrm{~mm}^{3}$. Mortar specimens with chloride salt content of $0.50 \%, 0.75 \%, 1.00 \%$ and $1.25 \%$ of cementing materials were formed. The working electrodes in mortar specimens were prepared by machining, polishing, and cleaning HPB235 alloy steel. The size of the electrodes was $\phi 7 \times 40 \mathrm{~mm}$. The auxiliary electrodes were stainless steel sheets with a size of $\phi 7 \times 40 \mathrm{~mm}$. The cover concrete thickness was $31.5 \mathrm{~mm}$. After one day of standing, the molds were removed. The porosity of the samples was tested after curing to $28 \mathrm{~d}$. Then the specimens dried in an oven with a temperature of $50 \pm 2{ }^{\circ} \mathrm{C}$ for 24 hours. Polishing one side of the test blocks when they were cooled to room temperature. Painting different times of PCI-2016 on these sides in different groups. The coating amount per time was $250 \mathrm{~g} / \mathrm{m}^{2}$.

Table 1. The chemical composition of cement.

\begin{tabular}{cccccccc}
\hline Composition & $\mathrm{SiO}_{2}(\mathrm{~S})$ & $\mathrm{Fe}_{2} \mathbf{O}_{\mathbf{3}}(\mathrm{F})$ & $\mathrm{Al}_{\mathbf{2}} \mathbf{O}_{\mathbf{3}}(\mathrm{A})$ & $\mathbf{C a O}(\mathrm{C})$ & $\mathbf{M g O}(\mathbf{M})$ & $\mathbf{S O}_{3}(\mathbf{S})$ & Others \\
\hline Content $\%$ & 21.63 & 3.6 & 3.95 & 64.68 & 2.99 & 2.01 & 1.13 \\
\hline
\end{tabular}

Table 2. The mechanical properties and porosity of mortar.

\begin{tabular}{ccccc}
\hline \multicolumn{2}{c}{ Compressive strength/(MPa) } & \multicolumn{2}{c}{ Rupture strength/(MPa) } & Porosity $(\%)$ \\
\hline $3 \mathrm{~d}$ & $28 \mathrm{~d}$ & $3 \mathrm{~d}$ & $28 \mathrm{~d}$ & \\
29.7 & 61.5 & 6.4 & 9.1 & 8.9 \\
\hline
\end{tabular}

\section{Parameter determination of $M C I$}

The chemical parameters of PCI-2016 at room temperature are shown in Table 3. The saturated vapor pressure values of PCI-2016 at different temperatures are shown in Table 4.

Table 3. Chemical parameters of PCI-2016.

\begin{tabular}{cccc}
\hline $\begin{array}{c}\text { Liquid density } \\
\boldsymbol{\rho}_{\mathbf{l}}\left(\mathbf{k g} / \mathbf{m}^{\mathbf{3}}\right)\end{array}$ & $\begin{array}{c}\text { Gas density } \\
\boldsymbol{\rho}_{\mathbf{v}}\left(\mathbf{k g} / \mathbf{m}^{\mathbf{3}}\right)\end{array}$ & $\begin{array}{c}\text { Surface tension } \\
\gamma(\mathbf{m N} / \mathbf{m})\end{array}$ & $\begin{array}{c}\text { Viscosity } \\
\boldsymbol{\mu}(\mathbf{P a} \cdot \mathbf{s})\end{array}$ \\
\hline 0.989 & 0.216 & 37.4 & 0.005 \\
\hline
\end{tabular}


Table 4. Test results for saturated vapor pressure of PCI-2016.

\begin{tabular}{cccccc}
\hline Temperature (Celsius degree) & $\mathbf{2 0}$ & $\mathbf{2 5}$ & $\mathbf{3 0}$ & $\mathbf{3 5}$ & $\mathbf{4 0}$ \\
\hline Saturated vapor pressure $(\mathrm{Pa})$ & 4180 & 5220 & 5960 & 6660 & 7350 \\
\hline
\end{tabular}

Nitrogen content test

The concentrations of nitrogen in different thickness of concrete samples after coated were measured by Kjeldahl method. The nitrogen contents at interface region between steel bar and concrete were also tested by the same method. Specific method refers to the Soil quality - determination of total nitrogen - Modified Kjeldahl method (HJ717-2014) [17].

\section{Electrochemical analysis}

The mortar specimens with chloride salt content of $0.50 \%, 0.75 \%, 1.00 \%$ and $1.25 \%$ were coated with once, twice, triple and quartic $(1.25 \mathrm{~g}, 2.5 \mathrm{~g}, 3.75 \mathrm{~g}$ and $5 \mathrm{~g})$ PCI-2016 respectively. The linear polarization resistance (LPR) and electrochemical impedance spectroscopy (EIS) of the work electrode were tested by the PARSTAT 2273 test system after coated $1 \mathrm{~d}, 3 \mathrm{~d}, 7 \mathrm{~d}, 14 \mathrm{~d}$ and $28 \mathrm{~d}$ at room temperature. The corrosion current density $\left(I_{\text {corr }}\right)$ was calculated by the Stern-Geary relationship [18].

$$
I_{\text {corr }}=B / R_{\mathrm{p}}
$$

Where the constant $B$ was obtained from the anodic and cathodic Tafel slopes and $R_{\mathrm{p}}$ was the measured polarization resistance.

\section{Results and discussion}

\section{Model calculation results}

In this numerical analysis, the temperature was $20^{\circ} \mathrm{C}$. The PCI-2016 concentrations in liquid phase at the gas-liquid interface were expressed as nitrogen element contents. The results of the short-term liquid phase model are shown in Table 5. According to the calculation results, the depth of the gas-liquid interface and the concentration of nitrogen content showed an upward trend with the increase of coating applications.

Table 5. Computational results of the short-term liquid phase model.

\begin{tabular}{cccc}
\hline $\begin{array}{c}\text { Coating } \\
\text { applications }\end{array}$ & $\begin{array}{c}\text { Surface drying } \\
\text { time (h) }\end{array}$ & $\begin{array}{c}\text { Distance between gas-liquid } \\
\text { interface and coated surface (mm) }\end{array}$ & $\begin{array}{c}\text { Concentration of nitrogen in } \\
\text { gas-liquid interface (mg/kg) }\end{array}$ \\
\hline 1 & 4 & 3.4 & 260 \\
2 & 8 & 5.2 & 350 \\
3 & 12 & 6.0 & 445 \\
4 & 16 & 6.8 & 630 \\
\hline
\end{tabular}


The distributions of nitrogen concentration in concrete specimens coated one to four applications are calculated by gas phase diffusion model. The results are shown in Figure 1. It can be found that in the same water to cement ratio, the more applications of PCI-2016 coating, the greater the penetration depth and permeation amount.

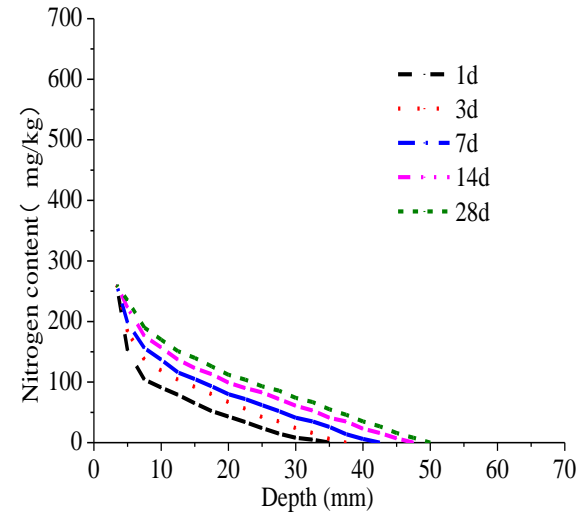

(a) Coated once (1.25 g) of PCI-2016

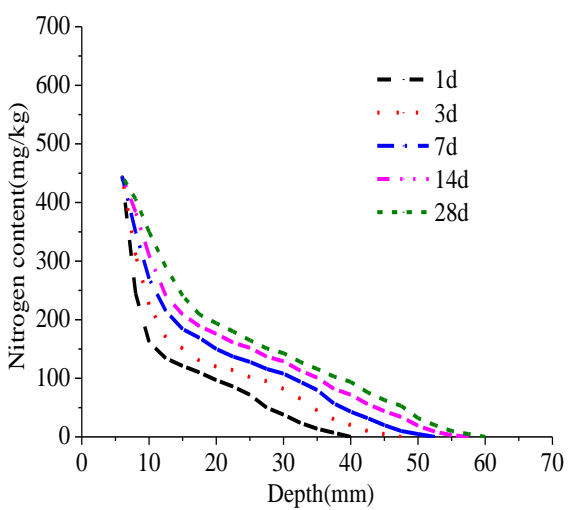

(c) Coated triple (3.75 g) of PCI-2016

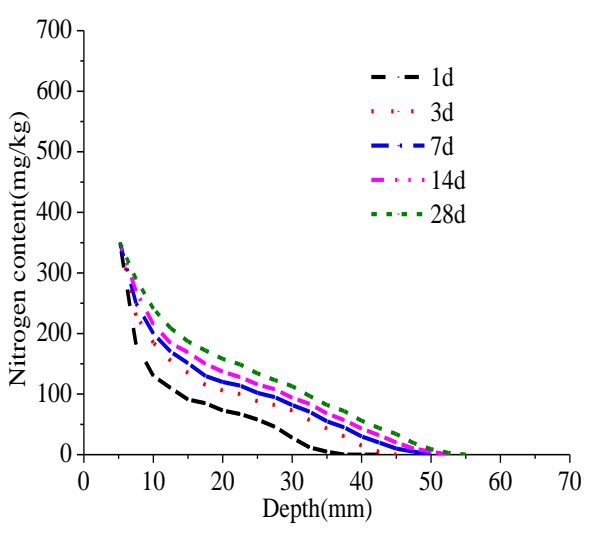

(b) Coated twice (2.5 g) of PCI-2016

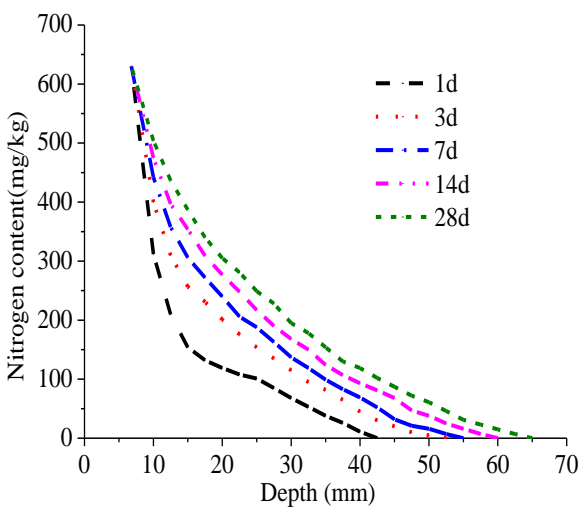

(d) Coated quartic (5 g) of PCI-2016

Figure 1. Distributions of nitrogen content calculated by the long-term gas diffusion model.

\section{Test result of Kjeldahl method}

Figure 2 shows the concentration of nitrogen measured by Kjeldahl method at different thickness of concrete cover ( $5 \mathrm{~mm}, 10 \mathrm{~mm}, 15 \mathrm{~mm}, 20 \mathrm{~mm}, 25 \mathrm{~mm}, 35 \mathrm{~mm}, 45 \mathrm{~mm}$ ) after coating one to four applications PCI-2016 on the surface of test block. It can be seen that the mass transfer process of PCI-2016 in the cover concrete is a mass transfer process with moving boundaries. The peak content gradually moves deeper into cover concrete over time. The peak value is gradually weakening as time goes on, this may because of the 
volatilization of corrosion inhibitor. The variation law of nitrogen content in the interface area between steel bar and concrete can be described by the above model.
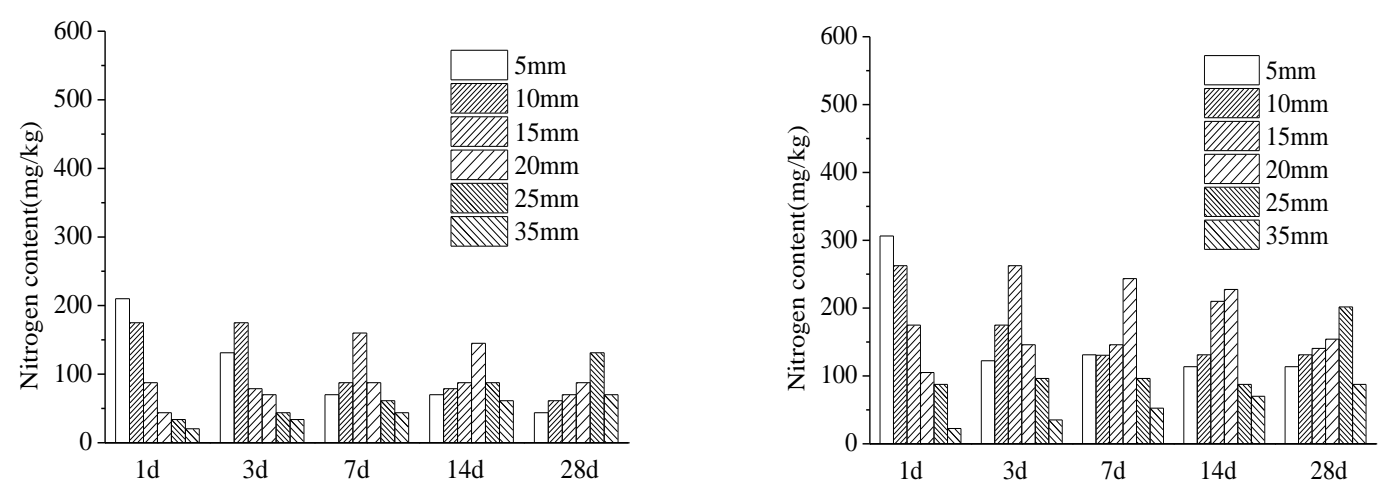

(a) Coated once (1.25 g) of PCI-2016

(b) Coated twice (2.5 g) of PCI-2016
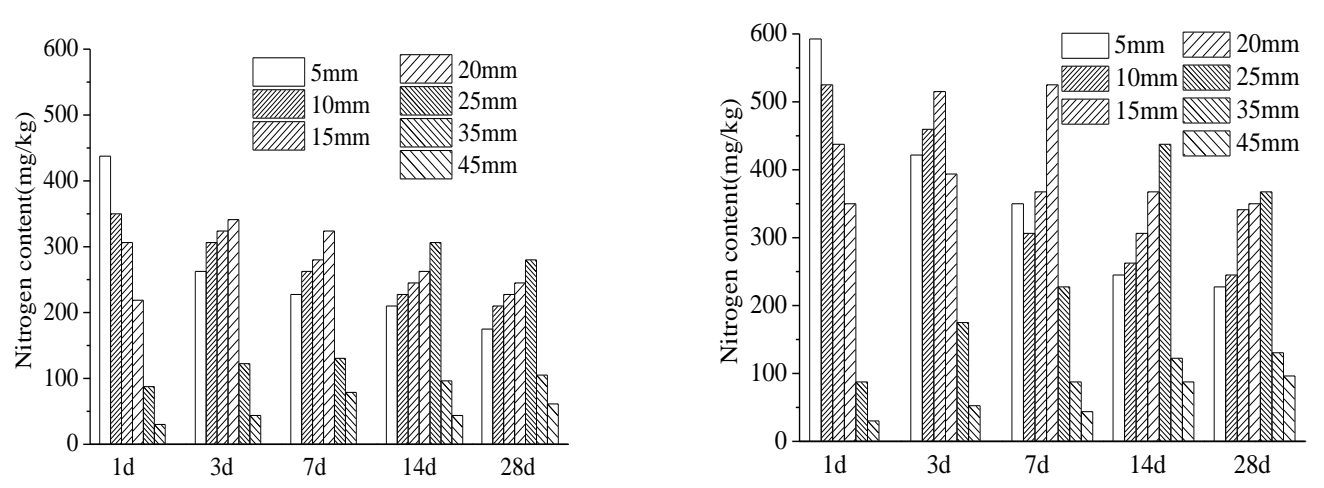

(c) Coated triple (3.75 g) of PCI-2016

(d) Coated quartic (5 g) of PCI-2016

Figure 2. Mass transfer process of PCI-2016 coating on mortar surface tested by Kjeldahl method.

\section{Nitrogen content concentration comparison}

The concentrations of nitrogen in the interface area between the reinforcement and mortar are measured by the Kjeldahl method. Compared with the experimental values and the calculated values obtained by the transmission model, the contrast results are shown in Figure 3. It can be obtained that the calculated results are in close compliance with the experimental results, which indicating that this transfer numerical analysis can be used to calculate the penetrating weight of PCI-2016 in the interface region between steel bar and concrete. 


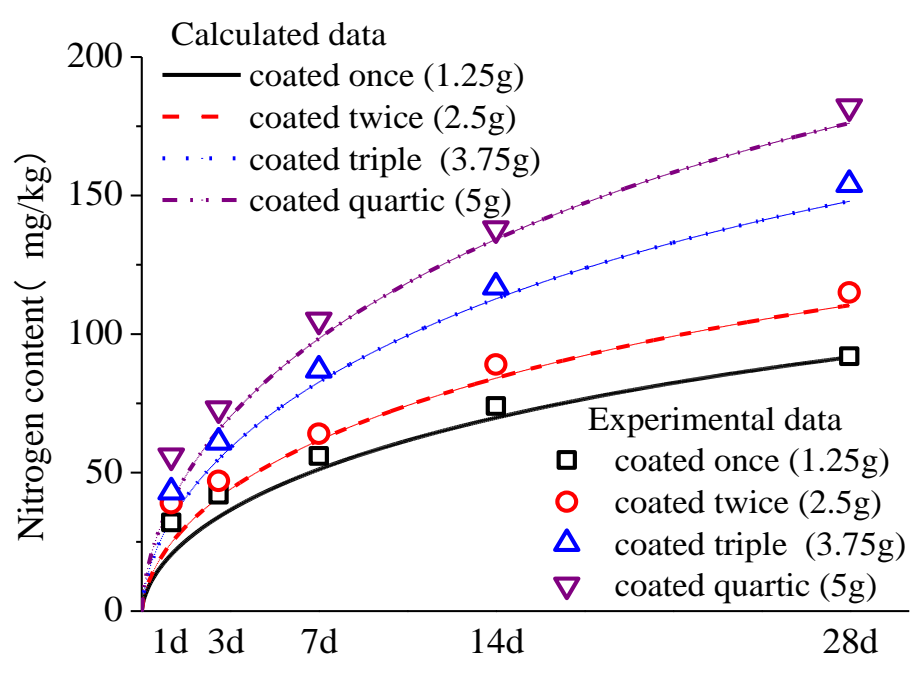

Figure 3. Comparison of experimental value and numerical simulation value.

\section{Electrochemical properties of steel bars}

According to the calculation results of the model, the rust inhibitor can be well transmitted to the surface of steel bar after coated PCI-2016. Corrosion of steel bars coated with a certain amount of corrosion inhibitor still needs to be tested by electrochemical experiments. The linear polarization resistance and $I_{\text {corr }}$ of steel electrode in specimens with different chlorine contents after coated the PCI-2016 are plotted in Figure 4. It can be seen that the initial $I_{\text {corr }}$ of the working electrode was low when the chloride concentration was low. As the PCI-2016 coated on the surface of the specimen moved inward continuously, the value of LPR was increased from the initial $200,000 \Omega \cdot \mathrm{cm}^{2}$ to more than $1,800,000 \Omega \cdot \mathrm{cm}^{2}$. As a result, the $I_{\text {corr }}$ of the electrode after coating PCI-2016 for $1 \mathrm{~d}$ was reduced to less than $0.1 \mu \mathrm{A} \cdot \mathrm{cm}^{-2}$. When the concentration of water-soluble chloride ion was high, the initial $I_{\text {corr }}$ of the working electrode was very large, and the working electrode was seriously corroded. The repair speed of PCI-2016 was slow, but after 28 days of coating, the steel bar can be repaired. The results indicated that PCI-2016 had an excellent anticorrosion ability. The Nyquist and Bode phase diagrams of an electrode in specimens with different chlorine contents are shown in Figure 5. Obviously, the radius of the Nyquist curve shown in Figure 5(a) was increasing with time after coated inhibitor, and the phase angle was also obviously enhanced. The results of the EIS test were consistent with the results of LPR. 


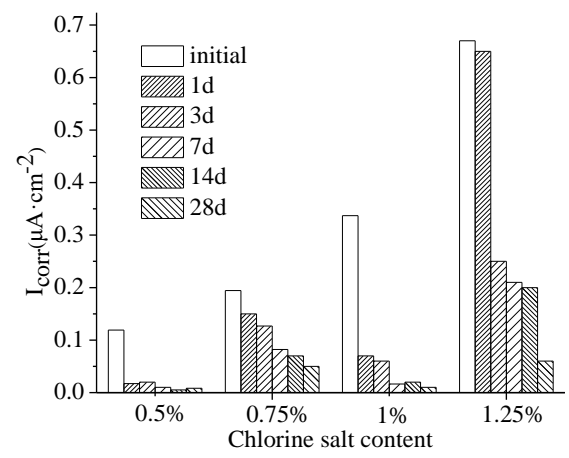

(a) Corrosion current density

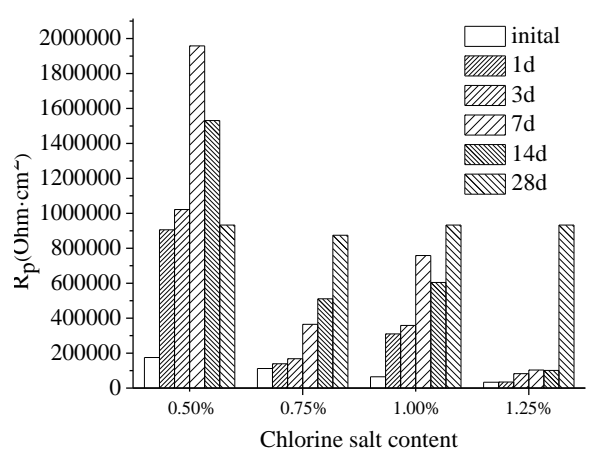

(b) Linear polarization resistance

Figure 4. Linear polarization resistance and $I_{\text {corr }}$ of steel electrode in specimens with different chlorine contents.

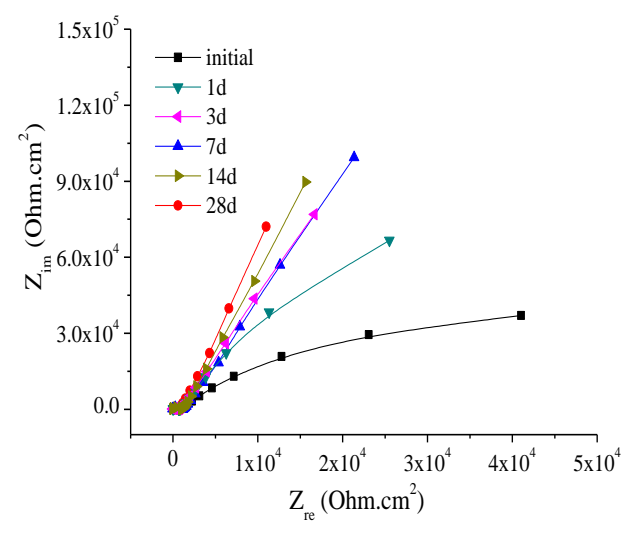

(a) Nyquist diagram

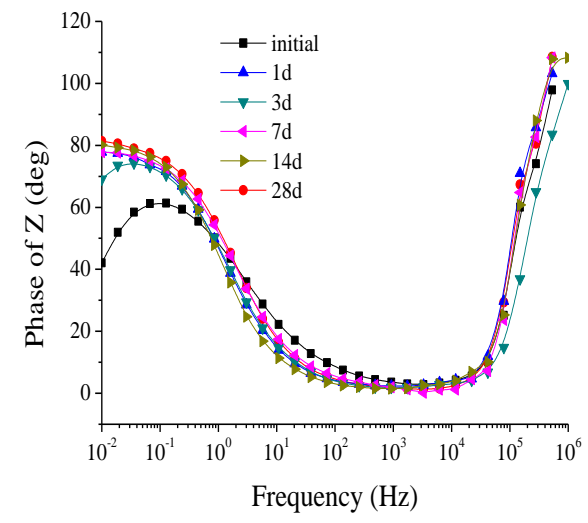

(b) Bode phase diagram

$(0.50 \% \mathrm{NaCl})$

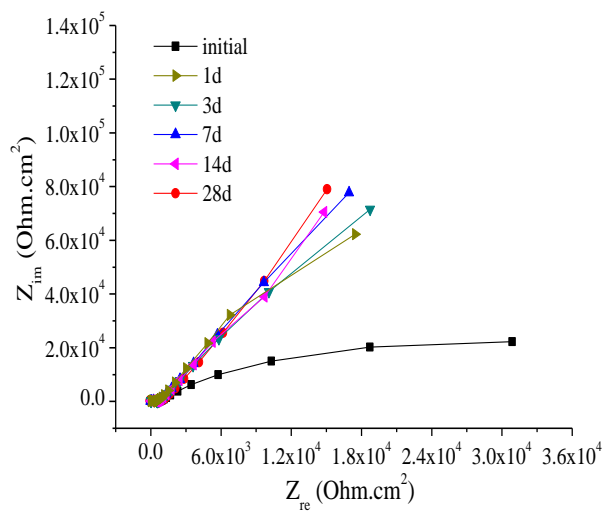

(a) Nyquist diagram

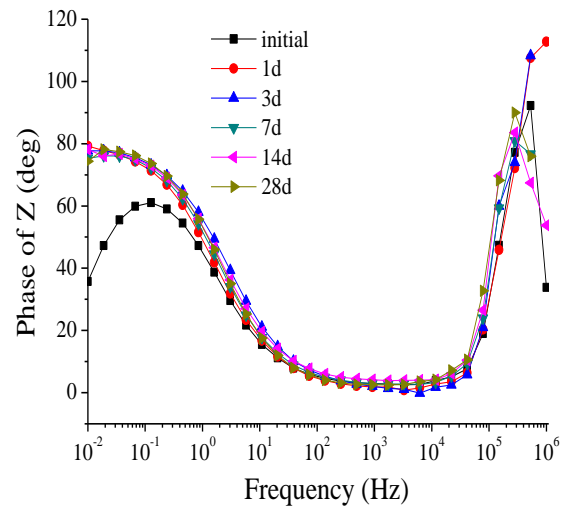

(b) Bode phase diagram 


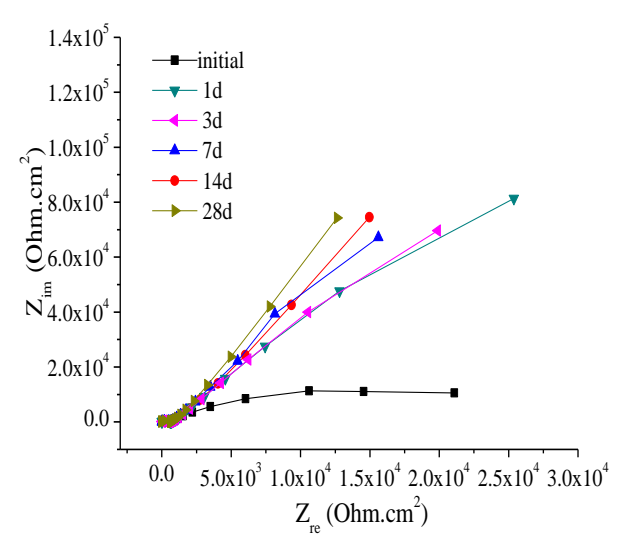

(a) Nyquist diagram

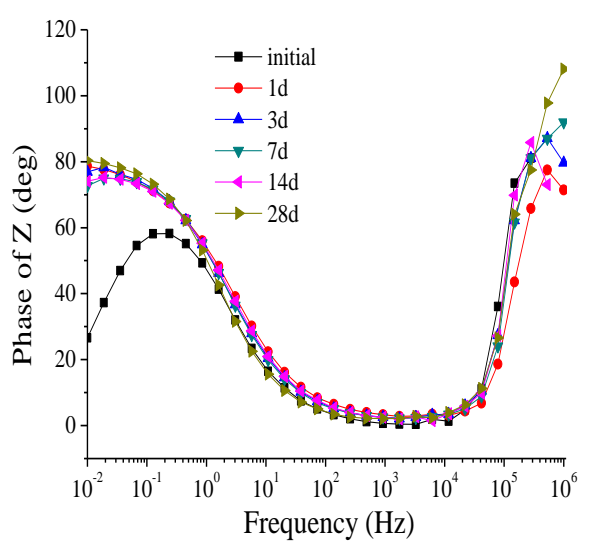

(b) Bode phase diagram

$(1.00 \% \mathrm{NaCl})$

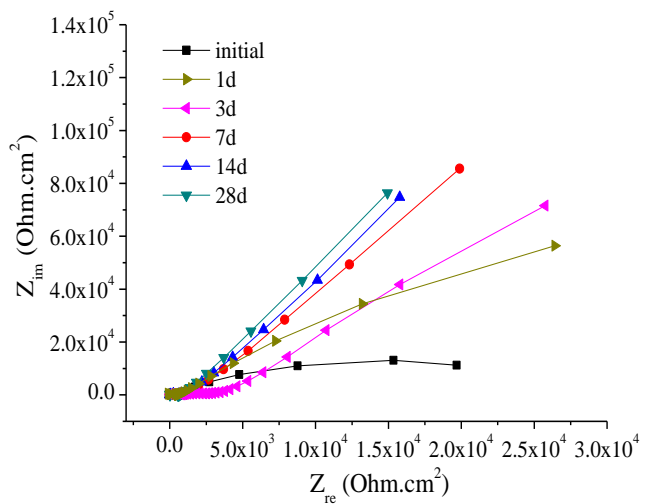

(a) Nyquist diagram

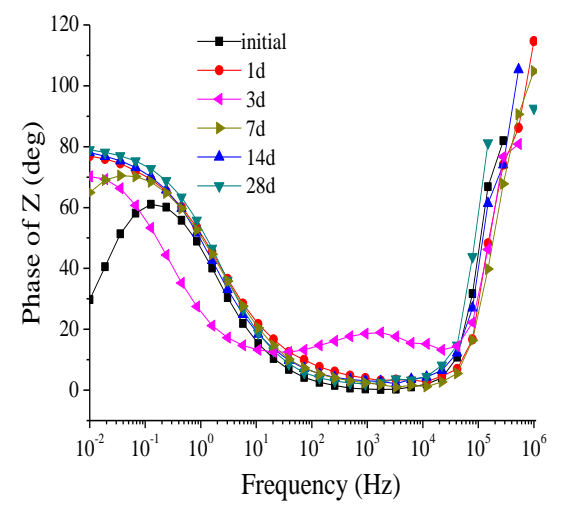

(b) Bode phase diagram

$(1.25 \% \mathrm{NaCl})$

Figure 5. EIS of steel electrode in specimens with different chlorine contents.

\section{Conclusion}

1. In the same water to cement ratio, the depth of gas liquid interface and the concentration of liquid nitrogen showed an upward trend. The peak gradually moved deeper into the cover concrete over time. The mass transfer process of the concrete surface-coated PCI-2016 is a mass transfer process with moving boundaries.

2. The concentration of nitrogen in the interface zone between steel bar and the concrete calculated by the transport model is consistent with the tested concentration of nitrogen measured by Kjeldahl method. The results show that the model can be used to simulate the penetrating weight of PCI-2016 in the interface zone between steel bar and concrete. This work is helpful to guide the engineering application of MCI in practical projects. 
3. The corrosion degree of steel bar in mortar increases with the increase of chloride content in mortar. After the PCI-2016 is coated on the mortar surface, the corroded steel bar is repaired with the rust inhibitor moving inward continuously. The results indicated that PCI-2016 has an excellent migration and anticorrosion ability.

\section{Acknowledgments}

Thanks for the financial support from National Natural Science Foundation of China (51278443, 51678512).

\section{References}

1. L. Holloway, K. Nairn and M. Forsyth, Concentration monitoring and performance of a migratory corrosion inhibitor in steel-reinforced concrete, Cem. Concr. Res., 2004, 34, no. $8,1435-1440$.

2. M. Ormellese, L. Lazzari, S. Goidanich, G. Fumagalli and A. Brenna, A study of organic substances as inhibitors for chloride-induced corrosion in concrete, Corros. Sci., 2009, 51, no. 12, 2959-2968.

3. T.A. Levasy, C. Manically and M.G. Richardson, The effect of a new generation surface-applied organic inhibitor on concrete properties, Cem. Concr. Compos., 2007, 29, no. 5, 357-364.

4. M.V. Diamanti, E.A. Pérez Rosales, G. Raffaini, F. Ganazzoli, A. Brenna, M. Pedeferri and M.Ormellese, Molecular modelling and electrochemical evaluation of organic inhibitors in concrete, Corros. Sci., 2015, 100, 231-241.

5. W. Shi, T.-Z. Wang, Z.H. Dong and X.-P. Guo, Application of wire beam electrode technique to investigate the migrating behavior of corrosion inhibitors in mortar, Constr. Build. Mater., 2017, 134, 167-175.

6. Z.Y. Liu, N. Song and Z.X. Wang, Properties and Characterization on a Novel Aqueous Inhibitor for Inhibiting Alloy Steel Corrosion in Chloride Solution, ASCE J. Mater. Civ. Eng., 2017, 29, no. 9, 04017136.

7. L. Yu, Z.Y. Liu, W.B. Yang and Z. Wang, Adsorption and characterization of an organic corrosion inhibitor for inhibiting carbon steel corrosion in chloride solution, Curr. Anal. Chem., 2016, 12, no. 2, 141-146.

8. Z.Y. Liu, L. Yu and Q.Z. Li, Synergic mechanism of an organic corrosion inhibitor for preventing carbon steel corrosion in chloride solution, J. Wuhan Univ. Technol., 2015, 30, no. 2, 325-330.

9. Z. Liu, L. Yu, Z. Wang and W. Yang, Modeling and experimental validation of MCI transport involving pore-blocking effect in cement-based materials. J. Mater. Civ. Eng., 2015, 28, no. 5, 04015187. doi: 10.1061/(ASCE)MT.1943-5533.0001455

10. Z.Y. Liu, Z.X. Wang and N. Song, A quantitative study on MCI rehabilitating steel bars in chloride contaminated concrete based on inhibition and transport behaviors, ASCE J. Mater. Civ. Eng., 2016, 28, no. 12, 04016172. 
11. W.B. Yang, L. Yu, Z.Y. Liu, Z.X. Wang and N. Song, Quantitative model and application of migration corrosion inhibitor affecting corrosion rate of steel bar, J. Chin. Ceram. Soc., 2015, 43, no. 6, 839-844 (in Chinese). doi: 10.14062/j.issn.04545648.2015.06.21

12. Z.X. Wang, L. Yu, Z.Y. Liu and N. Song, Effects of organic corrosion inhibitor and chloride ion concentration on steel depassivation and repassivation in solution, J. Chin. Ceram. Soc., 2015, 2, no. 3, 163-169. doi: 10.7521/j.issn.2095-7645.2015.03.08

13. Z.Y. Liu, Z.X. Wang and N. Song, Optimization of migrating corrosion inhibitor and its permeability and corrosion resistance, J. Chin. Ceram. Soc., 2016, 44, no. 3, 481-486 (in Chinese). doi: 10.14062/j.issn.0454-5648.2016.03.22

14. N. Song, Z. Wang, Z. Liu, J. Zhou and D. Zheng, Study on improvement of durability for reinforced concrete by surface-painting migrating corrosion inhibitor and engineering application, Mater. Sci. Eng., 2017, 167, 1-5.

15. T.A. Levasy, C. Manically and M. Richardson, Gather effect of a new generation surface-applied organic inhibitor on concrete properties, Cem. Concr. Compos., 2007, 29, no. 5, 357-364.

16. Z.Y. Liu, C.W. Miao, W.L. Zhou and J.P. Liu, Effect of migrating corrosion inhibitor on durability of concrete structures, J. Chin. Ceram. Soc., 2008, 36, no. 10, 1494-1500 (in Chinese). doi: 10.3321/j.issn:0454-5648.2008.10.028

17. HJ717-2014, Soil quality - Determination of total nitrogen - Modified Kjeldahl method, 2014.

18. A. Poursaee, Potentiostatic transient technique, a simple approach to estimate the corrosion current density and Stern-Geary constant of reinforcing steel in concrete, Cem. Concr. Res., 2010, 40, no. 9, 1451-1458. 